\title{
Moment resisting connections composed of friction-welded spruce boards: experimental investigations and numerical strength prediction
}

\author{
Benjamin Hahn • Till Vallée • Bernhard Stamm • \\ Yves Weinand
}

Received: 23 October 2013/Published online: 14 December 2013

(C) Springer-Verlag Berlin Heidelberg 2014

\begin{abstract}
Research on friction welded wood-to-wood connections has shown high potential for further development regarding the industrial application of timber construction. This paper addresses the question to which extent welding of wood can be applied to fabrication of crosslaminated timber panels (CLT). Those panels can be used as wall elements, in which load transfer occurs by transmission of moments and shear stresses. For this purpose, experimental investigations on friction welded L-shaped specimens were carried out. The welded bond between the boards, arranged perpendicularly to their fibre directions, represents points of intersection of those CLT panels. The results allowed for (a) the determination of a fracture mechanism of welded timber connections under torsion, (b) the definition of a set of design parameters influencing the resulting joint strength and (c) the comparison between the performance of welded timber joints and those of commonly glued alternatives. The experimental investigations were compared to results obtained by numerical modelling, thus allowing a probabilistic strength prediction algorithm for predicting the joint capacity as a function of the surface size.
\end{abstract}

\section{Moment übertragende Verbindungen aus reibgeschweißten Fichtenbrettern: Experimentelle Un- tersuchungen und numerische Festigkeitsbestimmung}

Zusammenfassung Bisherige Forschung an reibgeschweißten Holzverbindungen hat ein hohes Potenzial

B. Hahn $(\bowtie) \cdot$ B. Stamm · Y. Weinand

Laboratory for Timber Construction IBOIS, Ecole Polytechnique

Fédérale de Lausanne, 1015 Lausanne, Switzerland

e-mail: Benjamin.Hahn@epfl.ch

T. Vallée

Fraunhofer IFAM, Wiener Straße 12, 28359 Bremen, Germany für die weitere Entwicklung der Technologie in Richtung industrieller Anwendung im Holzbau gezeigt. Dieses Papier befasst sich mit der Frage, in welchem Umfang das Verfahren für die Herstellung von Brettsperrholzplatten (Cross Laminated Timber-CLT) angewendet werden kann. Diese Platten können als Wandelemente verwendet werden, in denen die eingeleiteten Horizontalkräfte in Form von Schubspannungen infolge Torsionsbeanspruchung in den Kreuzungspunkten abgeleitet werden. $\mathrm{Zu}$ diesem Zweck wurden experimentelle Untersuchungen an reibgeschweißten L-förmigen Versuchskörpern durchgeführt. Die geschweißte Verbindung zwischen den Brettlagen, die senkrecht zu ihren Faserrichtungen angeordnet sind, stellt einen Kreuzungspunkt von solchen CLT-Panels dar. Die Ergebnisse ermöglichten es, (a) einen Versagensmechanismus der geschweißten Holzverbindungen unter Torsion zu bestimmen, (b) einen Satz von Design-Parametern zu definieren, die die resultierende Festigkeit beeinflussen, und (c) die Kapazität von geschweißten Holzverbindungen mit allgemein verklebten Alternativen zu vergleichen. Die experimentellen Untersuchungen wurden mit den Ergebnissen von numerischen Modellierungen verglichen, wobei ein probabilistischer Algorithmus zur Vorhersage der Festigkeit in Abhängigkeit von der Größe der Oberfläche entwickelt wurde.

\section{Introduction}

\subsection{Load-bearing timber joints}

In recent decades, large-scale wood-based materials have appeared on the market opening new possibilities for architects and engineers to realise innovative conceptual designs of structures (Weinand 2009). In particular cross 
laminated timber panels (CLT) constitute, in combination with modern prefabrication techniques, new perspectives of timber construction. So far, specifically formulated chemical adhesives based on polyurethane (PU) are used in order to connect the different layers of the stratified material, creating powerful planar joints. Glued timber joints based on aforementioned adhesives exhibit high mechanical performance. In general, the resistance of the joint is higher than that of the timber itself. However, glued components lead to higher abrasion of cutting tools during machining processes. Furthermore, there are still concerns about their impact on health and environment during application as well as at later disposal at the end of the expected useful life of the building. A promising alternative is the adhesive-free bonding method of friction welding of wood, which has been intensively investigated for some time at the IBOIS (Gliniorz and Natterer 2000; Illing 2002; Stamm et al. $2005 a$, b) together with other research institutions in Switzerland and France (Delmotte et al. 2009; Pizzi et al. 2011). Very briefly, during friction welding the contact surface between two components is heated by a fast frictional movement and thereby fused to a thermally modified contact layer in a very short time. Preliminary investigations showed interesting potentials of the procedure (Stamm and Weinand 2006). The question whether, and to which extent, the technique can be applied to the production of constructional elements, remains the focus of ongoing research.

\subsection{Welding of wood}

Welding of wood is based on the same principles as conventional friction welding technologies commonly used for metals and thermoplastics: Two elements are rubbed against each other by a combination of normal pressure $P$ and an oscillating friction movement with a frequency $f$ and an amplitude $a$. As a result, the interface is heated up quickly and thermo-chemical decomposition, pyrolysis, of the organic material (lignin, cellulose and hemicelluloses) is taking place within seconds (Stamm et al. 2005c). The frictional movement stops after a predefined welding time or, alternatively, welding displacement. The latter describes the path the two components approach each other due to the thermal transformation, compression and material loss in the contact area. When friction is stopped the interface is let to cool down while maintaining a cooling pressure on the sample. Consequently the thermally decomposed material hardens, forming a dark and firm contact layer. Since the welding process is completed in less than a minute, stratified elements made of timber layers can be welded continuously (Stamm et al. 2005b).
The layers can be welded with parallel and perpendicular orientation of the grains resulting in different characteristics of the joint (Properzi et al. 2005).

Two groups of parameters influencing the welding result can be distinguished: first, machine settings like $P, f$ and $a$ related to the welding device; second, anatomical parameters related to the characteristics of the wood, influenced by the species, year ring orientation, moisture content, density and sample size.

Two frictional movements can be distinguished: circular and linear vibration. Former investigations showed that linear vibration welding (LVW) leads to better mechanical characteristics of the connection when the two boards are orientated parallel to the fibre direction (Gfeller et al. 2003). Welded bonds of perpendicular orientated timber boards however have not been investigated in detail up to now.

\subsection{Strength prediction of welded timber joints}

Experimental evidence (Gliniorz and Natterer 2000; Illing 2002; Stamm et al. 2005a, b; Properzi et al. 2005; Gfeller et al. 2003) clearly indicates that frictional welding leads to joints with a very stiff bond, associated joint failure occurs in a very sudden and brittle manner. Brittle, respectively quasi-brittle, failure indicates a strong dependency of strength and size, commonly labelled size effects, first introduced by (Weibull 1939) and subsequently developed by his followers (Freudenthal 1968; Bažant et al. 1991; Bazant 2005). Size effect based prediction of brittle bonds have since then been successfully formulated for, amongst other materials, fibre reinforced polymer (FRP) (Keller and Vallée 2006) and timber (Tannert et al. 2012); and for axially loaded friction welded timber joints by Vallée et al. (2011), respectively Hahn et al. (2012).

The basis of predicting joint strength is the accurate determination of the stress-strain state in the welded interface. Failure of rigid joints is usually associated with stress peaks of transverse tensile stresses and shear stresses towards the edges (Suzuki 1987). For axially loaded lap joints, Da Silva et al. (2009a, b) compared different analytical methods for estimating the stress-strain distribution in the interface. Although the problem of torsion and stresses generated thereupon has been treated analytically and the authors are aware of the work of St. Venant and his followers, closed-form solutions do only exist for a quite limited range of geometrical shape, and mostly for idealized loadings (pure torsion) and isotropic material. With regard to the investigation on moment resisting joints, the subject of the present study, no analytical solutions exist that take into account the complexity of the calculations, caused by factors such as anisotropic material properties of 
timber and a three-dimensional vector and that consider strong size effects. Thus, Finite Element Analysis (FEA) has to be preferred over analytical determination in order to overcome the limitations of analytical methods. Despite of the latter, results will be compared to a standard linear elastic stress analysis approach commonly used for stress verification in glued interfaces between layers of CLT panels (Blaß and Görlacher 2002).

Failure of friction welded assemblies occurs mainly within the welded interface. Thus a failure criterion for the interfacial layer has to be defined and applied to the capacity prediction algorithm. The characteristics of welded interfaces depend on specific welding parameters and cannot be generalised for each case. They were determined anew for the present investigations. Since the stress state is characterised by simultaneous occurrence of multiple stress components, the combined effect on the material strength has to be considered. Stress-based off-axis tests, successfully applied to two-dimensional studies on adhesively bonded double lap joints (Keller and Vallée 2006; Tannert et al. 2012; Vallée et al. 2011; Hahn et al. 2012), present a convenient alternative to energy release based concepts commonly used (Balzani et al. 2012; Pupurs et al. 2013).

Attempts to predict the load bearing capacity of adhesively bonded joints using stress based concepts are difficult because of the aforementioned stress concentrations towards singularities. If these stress peaks are predominant, predicted joint capacity based thereupon is highly underestimated. A promising approach to resolve these limitations is a nonlocal probabilistic strength prediction method described by Bažant et al. (2000a, b), in which capacity of the joints is reformulated in terms of probabilities of failures, which relieves the problematic associated with stress peaks.

\subsection{Objectives}

This paper aims to describe the structural behaviour of cross-wise friction welded bonds made of timber as a function of welding parameters and the geometrical design of the connection. The structural behaviour of such joints in horizontally loaded bracing CLT elements is investigated. Therefore the moment transmitting intersection points of such panels are represented by welded L-shaped specimens, where a torsional moment is introduced through a cantilever. The performance of welded joints is directly compared to adhesively bonded ones. Further, the joint's strength is mechanically characterized with regard to shear stresses resulting from torsion and transverse tensile stresses; the collected data is subsequently statistically treated to serve as input for a probabilistic strength prediction. A comparison between experimental and computed joint strengths concludes the paper.

\section{Experimental investigation}

\subsection{Material}

Samples of high quality, plane, and almost flawless, spruce (Picea abies) boards were used for the production of the specimens. Even if the presence of natural defects such as knots and resin slots cannot always be avoided within samples of bigger sizes, it was ensured that they don't occur within the welded zone. Previous tests showed that the scattering of the strength results can be decreased when samples with low moisture content are welded (Stamm et al. 2011). Therefore the samples were stored under dry climate conditions of $40{ }^{\circ} \mathrm{C}$ and $27 \%$ relative air humidity before welding, resulting in a low moisture content of $4 \%$. These conditions represent an idealised situation that is unlikely to occur in potential practical application; however, this restriction does not have an influence on the principles of the strength prediction approach, it only serves to diminish the scattering of the experimental results.

\subsection{Specimen description}

In order to investigate the moment resistance of planar wood welded connections symmetric triple-layered L-shaped specimens shown in Fig. 1 were considered. As the effect of joint size was investigated, the width of the boards, and thus the edge length of the bonded interface, was varied between 100, 130 and $160 \mathrm{~mm}$. In order to keep the distance between the geometrical centre of the interface and the point of load application constant, the length of the boards varied between 550 and $590 \mathrm{~mm}$; all geometrical parameters are listed in Table 1.

The assembling by friction welding was realised in a LZM 75 welding machine, a prototype designed by the company Fischer Schweisstechnik, in a two-step process. First, the middle layer was welded with perpendicular fibre orientation to the first of the two outer layers; once the interface was cured, the preliminary test specimens were stored for 1 day under the aforementioned dry climate conditions. In a next step the second outer layer was welded on the middle layer, parallelism with regard to the first outer layer was respected. An example of a specimen is shown in Fig. 1.

For the purpose of comparison, glued bonds were tested for samples with $100 \mathrm{~mm}$ edge length. Polyurethane based glue Collano Semparoc Rapid $S$ was applied on both compounds and pressure was maintained for 1 day by bar clamps. In order to facilitate the chemical reaction of the glue, the surface was humidified in the range of the bond. 

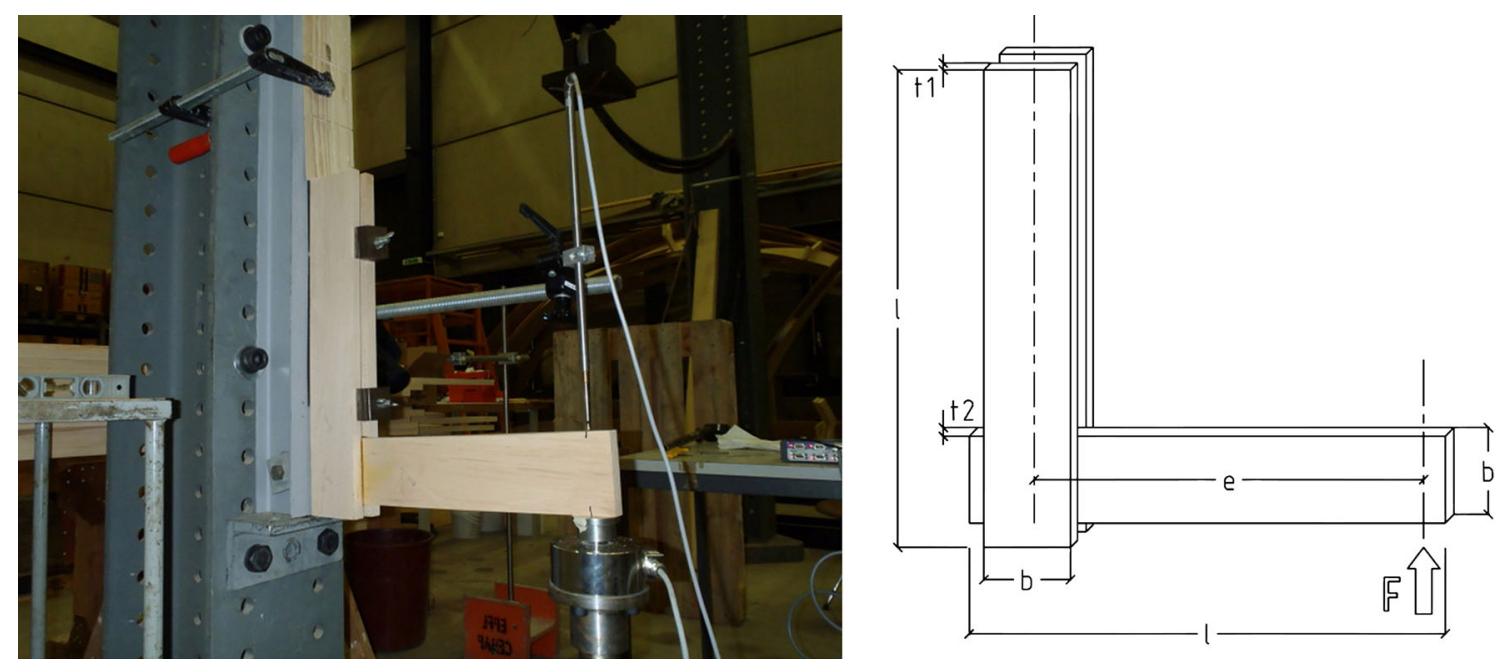

Fig. 1 Sample of a cross-wise welded L-specimen composed of spruce boards (left) and schematic layout of the samples (right), dimensions according to Table 1

Abb. 1 Beispiel eines kreuzweise verschweißten L-Probekörpers aus Fichtenbrettern (links) und schematische Darstellung der Proben (rechts), Abmessungen gemäß Tabelle 1

Table 1 Geometrical parameters of the L-shaped specimens according to Fig. 1

Tab. 1 Geometrische Angaben der L-förmigen Prüfkörper gemäß Abb. 1

\begin{tabular}{llllll}
\hline $\begin{array}{l}\text { Edge } \\
\text { length b } \\
(\mathrm{mm})\end{array}$ & $\begin{array}{l}\text { Surface } \\
\text { size A } \\
\left(\mathrm{mm}^{2)}\right.\end{array}$ & $\begin{array}{l}\text { Lifting } \\
\text { arm e } \\
(\mathrm{mm})\end{array}$ & $\begin{array}{l}\text { Board } \\
\text { length } 1 \\
(\mathrm{~mm})\end{array}$ & $\begin{array}{l}\text { Thickness } \\
\mathrm{t}_{1}(\mathrm{~mm})\end{array}$ & $\begin{array}{l}\text { Thickness } \\
\mathrm{t}_{2}(\mathrm{~mm})\end{array}$ \\
\hline 100 & 10,000 & 450 & 550 & 16 & 20 \\
130 & 16,900 & 450 & 570 & 16 & 20 \\
160 & 25,600 & 450 & 590 & 16 & 20 \\
\hline
\end{tabular}

\subsection{Welding parameters}

Prior to the fabrication of all test series, the question had to be addressed whether a linear or a circular vibrational movement is more adequate for cross-wise welded bonds. Therefore a set of preliminary tests was carried out according to Sect. 2.6 on specimens with an initial edge length of $100 \mathrm{~mm}$ (see Table 1). The welding parameters frequency $f$, pressure $P$, amplitude $a$, and welding displacement $d$ were determined for Linear Vibration Welding (LVW) during previous parametrical investigations and are listed in Table 2. Stamm et al. (2005a) proposed a formulation for the heat energy generated per surface unit during friction welding. In order to keep this amount of energy constant during a given time interval, the amplitude $a$ had to be modified with the transition from LVW to Circular Vibration Welding (ZVW). All parameters as well as the test results are provided in Table 2. It turned out that Circular Vibration Welding (ZVW) led to a higher average value for joint strength than Linear Vibration Welding (LVW). Even if the standard deviation for ZVW was higher than for LVW, it was decided to use the welding parameters for ZVW from Table 2 for further fabrication of the remaining specimens with an edge length of 130 and $160 \mathrm{~mm}$. The higher deviation resulted from one very weak and a second very high result of tested joint strength (see Fig. 2); discarding these elements would have reduced the scattering to $9 \%$.

\subsection{Characterisation of the timber}

The mechanical properties of the used timber were determined by means of an optical image correlation system (Pan et al. 2009). Axial tests were performed on dog-bone shaped samples exhibiting different fibre and year ring orientations. A random pattern of black spots on a white background was applied on the surface and scanned at different load steps. In a subsequent stress-strain evaluation using the Vic-3D ${ }^{\circledR}$ application from the company Correlated Solutions, the averaged material constants including standard deviations in longitudinal, radial and transversal direction, listed in Table 3, were determined.

Since failure always occurred within the friction welded bond, here a strength criterion has only been developed for the welded interface and not for the timber, refer to Sect. 2.3. Capacity prediction for glued samples using PU adhesives, in which a strength criterion of the timber becomes necessary, has been regarded in previous studies (Tannert et al. 2012; Serrano 2004) and was not envisaged here. They only serve for the purpose of comparison with the mechanical performance of the welded joints. 
Table 2 Experimental results for preliminary investigation on samples bonded by linear friction (LVW), circular friction (ZVW) and PUR bond Tab. 2 Experimentelle Ergebnisse der Voruntersuchung an Proben, die mittels linearen Reibschweißsens (LVW), zirkularen Reibschweißens (ZVW) sowie PUR-Bindern gefügt wurden

\begin{tabular}{llllllr}
\hline $\begin{array}{l}\text { Bonding } \\
\text { technology }\end{array}$ & $\begin{array}{l}\text { Welding pressure } \\
P(\mathrm{MPa})\end{array}$ & $\begin{array}{l}\text { Welding } \\
\text { displacement } d(\mathrm{~mm})\end{array}$ & $\begin{array}{l}\text { Welding } \\
\text { Frequency } f(\mathrm{~Hz})\end{array}$ & $\begin{array}{l}\text { Amplitude } \\
a(\mathrm{~mm})\end{array}$ & $\begin{array}{l}\text { Mean Resistance } \\
\mathrm{F}(\mathrm{kN})\end{array}$ & $\begin{array}{l}\text { Standard } \\
\text { Deviation }(\mathrm{kN})\end{array}$ \\
\hline LVW & 1.6 & 2.0 & 130 & 1.50 & 1.24 & 0.21 \\
ZVW & 1.6 & 2.0 & 130 & 0.96 & 1.66 & 0.44 \\
PUR Bond & & & & 4.31 & $28 \%$ \\
\hline
\end{tabular}

Bold fonts are indicates the modificaions during the review process
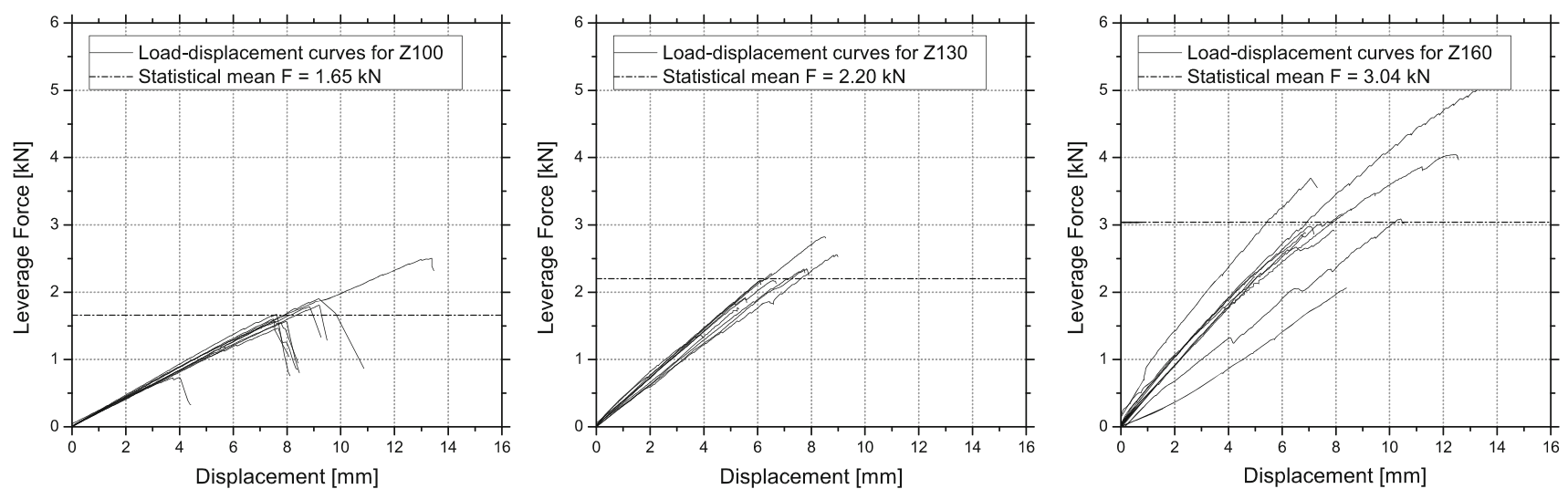

Fig. 2 Load-slip curves for different samples sizes including experimental mean value

Abb. 2 Kraft-Verformungs-Kurven für verschiedene Probengrößen einschließlich experimentellen Mittelwert

Table 3 Material constants and standard deviations of the timber samples used for the investigations

Tab. 3 Für die Untersuchungen verwendete Materialkennwerte und Standardabweichungen der Holzproben

\begin{tabular}{lllllll}
\hline Young's modulus & $\mathrm{E}_{\mathrm{L}}=10,950 \mathrm{MPa}$ & $\mathrm{COV}=19 \%$ & $\mathrm{E}_{\mathrm{T}}=630 \mathrm{MPa}$ & $\mathrm{COV}=24 \%$ & $\mathrm{E}_{\mathrm{R}}=490 \mathrm{MPa}$ & $\mathrm{COV}=19 \%$ \\
Shear modulus & $\mathrm{G}_{\mathrm{LR}}=330 \mathrm{MPa}$ & $\mathrm{COV}=10 \%$ & $\mathrm{G}_{\mathrm{RT}}=33 \mathrm{MPa}$ & & $\mathrm{G}_{\mathrm{LT}}=600 \mathrm{MPa}$ & $\mathrm{COV}=8 \%$ \\
Poisson coefficient & $\mu_{\mathrm{LR}}=0.6$ & $\mathrm{COV}=14 \%$ & $\mu_{\mathrm{RT}}=0.8$ & $\mathrm{COV}=4 \%$ & $\mu_{\mathrm{LT}}=0.4$ & $\mathrm{COV}=29 \%$ \\
\hline
\end{tabular}

\subsection{Interface characterisation}

Subjected to a bending moment, the welded bond is exposed to shear stresses, $\tau$, generated by the torsional moment, $\mathrm{M}$, and the shear force, $\mathrm{V}$. In addition, normal stresses, $\sigma$, orthogonal to the interface are also generated (Hermann 1965).

According to the brittle nature of the interface, failure of the joint occurs if the mechanical resistance of the weakest element is exceeded. Owing to the fact that two stress components, namely $\tau$ and $\sigma$, act simultaneously, it was necessary to derive a failure criterion of the welded interface for both components for further implementation to the procedure of strength prediction.

A series of tests was carried out on small cylindrical samples depicted in Fig. 3. The test setup allows for an almost homogeneously distributed torsional shear stress field, $\tau$, when both ends are rotated in opposite direction to each other. At the same time an almost constant tensile stress distribution, $\sigma$, can be achieved by means of a simultaneously performed traction test. For the sake of simplification it is assumed that the shear resistance of the interface is independent of the local fibre orientation. This approach is also justified by the fact that inside the welded connections shear stresses also do act under different angles with regard to fibre orientation, making the comparison between experimental setup and situation inside the welded joint feasible.

Since the cylinders could not be welded directly due to technical limitations of the welding machine, they were cut out from welded blocs of $100 \times 100 \times 90 \mathrm{~mm}^{3}$ by means of a high accurate computer numerical controlled (CNC) cutting machine. Figure 3 shows the resulting samples. One timber part with a thickness of $40 \mathrm{~mm}$ was welded with perpendicular fibre direction onto an opposite $50 \mathrm{~mm}$ thick element using the same parameters as for the L-specimens.

The specimens were tested for tensile and torsion using a MTS axial/torsional test system. First, the mechanical resistance for the two single stress states, i.e. pure torsion 
$\tau_{\mathrm{u}}$ and pure tensile $\sigma_{\mathrm{u}}$, were determined. For the combination of shear and tensile stresses two levels of prestressed tensile loads were defined and applied to the samples before testing, corresponding to approximately one-third and two-thirds of the mean resistance from previous simple tensile tests. Subsequently, a torsional moment was introduced into the specimen until failure occurred. The results are presented in Fig. 4.

\subsection{Tests on moment resisting L-specimens}

The wood welded specimens were taken out of the climatic chamber $\left(40{ }^{\circ} \mathrm{C}\right.$ and $25 \%$ relative air humidity) and tested in the test hall within a few minutes. Although the climate

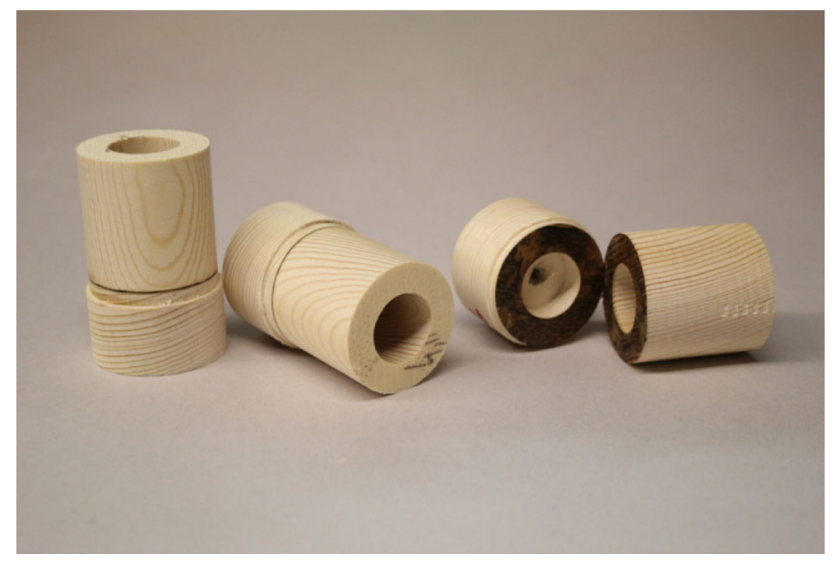

Fig. 3 Cylindrical specimens for interface characterisation of friction welded timber (inner radius $R_{i}=10 \mathrm{~mm}$, outer radius $R_{o}=38 \mathrm{~mm}$, wall thickness $\mathrm{t}=9 \mathrm{~mm}$, height $\mathrm{h}=90 \mathrm{~mm}$ )

Abb. 3 Zylinderförmige Probekörper für die Charakterisierung der Verbundfläche von reibgeschweißten Holzverbindungen (Innenradius $\mathrm{R}_{\mathrm{i}}=10 \mathrm{~mm}$, äußerer Radius $\mathrm{R}_{\mathrm{o}}=38 \mathrm{~mm}$, Wandstärke $\mathrm{t}=9 \mathrm{~mm}$, Höhe $\mathrm{h}=90 \mathrm{~mm}$ )

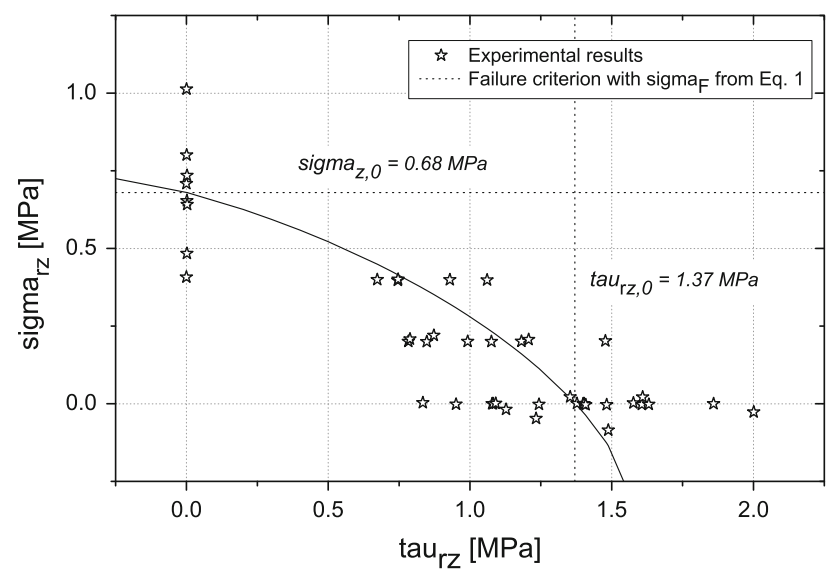

Fig. 4 Experimental results from off-axis tests and fitting curve for $\sigma \mathrm{F}=1$

Abb. 4 Experimentelle Ergebnisse der Off-Axis-Tests und Angleichskurve für $\sigma \mathrm{F}=1$ conditions during testing differed from those during storage (and could not be controlled) the influence of the changing conditions is considered negligible since the time lapse between the storage conditions and testing was kept short.

The test setup is illustrated in Fig. 1. The two outer layers were fixed with metal bolts on a vertical steel column. A hydraulic cylinder was used to introduce a force on the central horizontal board at a distance of $450 \mathrm{~mm}$ from the centre of the welded interface with a displacement rate of $2 \mathrm{~mm} / \mathrm{min}$, inducing the aforementioned stresses, $\tau$ and $\sigma$, at the interface. The displacement was increased up to failure load $F_{\text {ult }}$. Ten samples were tested for each size. The load displacement curves for samples welded wit ZVW are shown in Fig. 2. Failure occurred in a sudden and brittle manner within the welded bond without initial noticeable crack propagation. In general no residual load bearing capacity was observed; for very few specimens one of both welded interfaces stayed intact and a reduced load could still be transmitted. Nevertheless the load level of the first interface failure was taken into account and considered as ultimate load $\mathrm{F}_{\text {ult }}$.

\subsection{Experimental results}

Visual evaluations of the post-failure opened interface of the welded L-specimens as well as of the cylindrical offaxis samples showed satisfactory results in terms of the amount of thermally modified cell material within the bonded area. All samples showed homogeneously well darkened interfaces, indicating a good weld. Thus no specimen was rejected from the evaluation due to insufficient bonding. Until the brittle and sudden rupture, the L-shaped specimens showed almost perfectly linear-elastic load-displacement behaviour.

Table 2 lists the results as well as the standard deviation of the preliminary tests on specimens with $100 \mathrm{~mm}$ edge length. Linear and circular welding movement were distinguished and compared to glued bonds. Welded bonds obtained by circular friction (ZVW) yielded on average joint strengths approximately 1.3 times higher than those obtained by linear friction (LVW), expressed in numbers $1.66 \mathrm{kN}$ against $1.24 \mathrm{kN}$.

Glued samples did not fail in the bondline, but in the timber close to the overlap. The load-displacement curve showed linear progression up to the moment when the tensile stresses close to the bond exceed the material strength, and subsequently failed. As a consequence the load that could be applied on glued samples was $4.31 \mathrm{kN}$, on average, 2.6 times higher than for welded bonds.

Figure 5 shows the experimental data for the tested welded L-specimens plotted against the joint surfaces edge length L. Joint strength increases almost linearly with increasing joint size. In order to illustrate size effects, joint strengths were plotted against polar moment of inertia $\mathrm{I}_{\mathrm{P}}$ of 

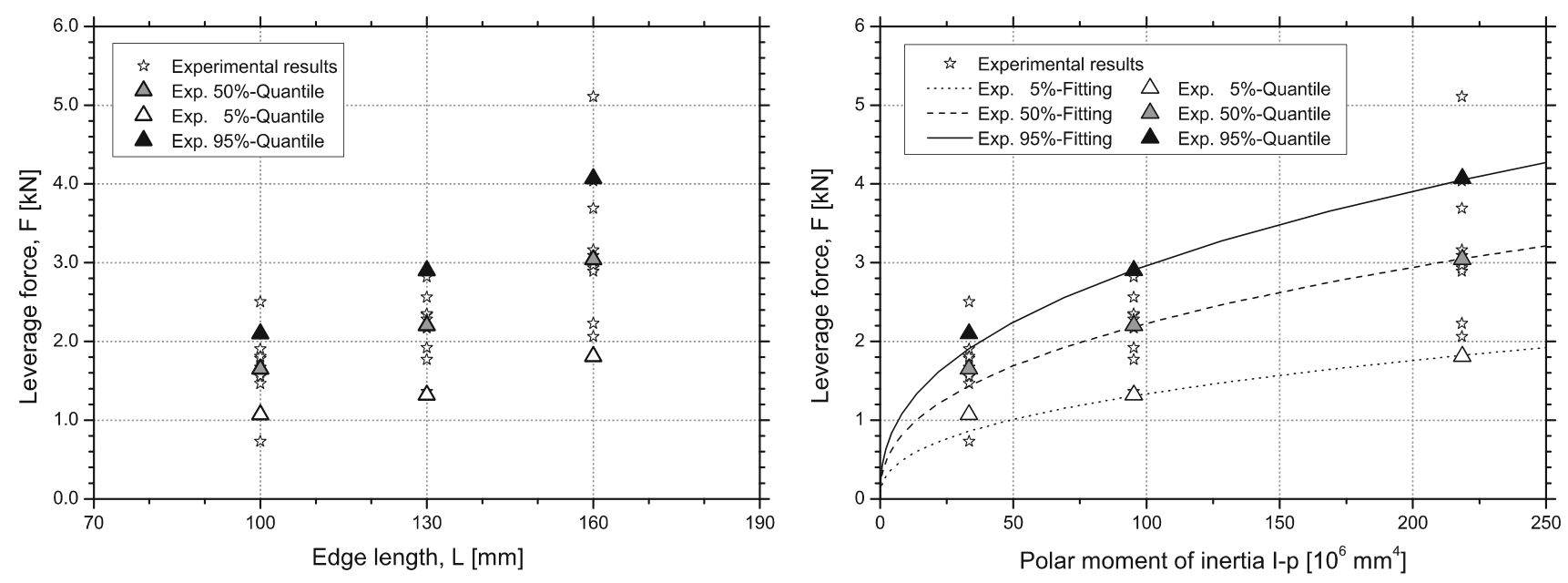

Fig. 5 Experimentally estimated load bearing capacity of L-specimens against bond edge length $\mathrm{b}$ (left) and against polar moment of inertia $\mathrm{I}_{\mathrm{P}}$ (right)

Abb. 5 Experimentell ermittelte Tragfähigkeit von L-Probekörpern bezogen auf Kantenlänge b (links) und bezogen auf das polare Trägheitsmoment $\mathrm{I}_{\mathrm{P}}$ (rechts)

Table 4 Experimental results and Numerical strength predictions, for both the average values and the upper and lower $5 \%$-quantile (all values in $\mathrm{kN}$ )

Tab. 4 Experimentelle Ergebnisse und numerische Festigkeitsbestimmungen der Mittelwerte als auch der oberen und unteren $5 \%$ Quantile (alle Werte in $\mathrm{kN}$ )

\begin{tabular}{|c|c|c|c|c|}
\hline Edge length (mm) & 100 & 130 & 160 & All \\
\hline $\begin{array}{l}\text { Polar moment of } \\
\text { inertia }\left(\mathrm{mm}^{4}\right)\end{array}$ & $3.33 \times 10^{7}$ & $9.52 \times 10^{7}$ & $2.18 \times 10^{8}$ & \\
\hline $\begin{array}{l}\text { Experimental mean } \\
(\mathrm{kN})\end{array}$ & 1.66 & 2.20 & 3.04 & \\
\hline $\begin{array}{l}\text { Standard deviation } \\
(\mathrm{kN})\end{array}$ & 0.44 & 0.41 & 0.89 & \\
\hline $\mathrm{COV}$ & $26 \%$ & $19 \%$ & $29 \%$ & $25 \%$ \\
\hline $\begin{array}{l}\text { Predicted mean } \\
(\mathrm{kN})\end{array}$ & 1.05 & 1.87 & 2.87 & \\
\hline Accuracy & $61 \%$ & $81 \%$ & $91 \%$ & $78 \%$ \\
\hline $\begin{array}{c}\text { Experimental } 5 \% \text { - } \\
\text { quantile }(\mathrm{kN})\end{array}$ & 1.07 & 1.32 & 1.81 & \\
\hline $\begin{array}{r}\text { Predicted } 5 \%- \\
\text { quantile }(\mathrm{kN})\end{array}$ & 0.67 & 1.16 & 1.79 & \\
\hline Accuracy & $60 \%$ & $87 \%$ & $98 \%$ & $82 \%$ \\
\hline $\begin{array}{l}\text { Experimental } 95 \% \text { - } \\
\text { quantile }(\mathrm{kN})\end{array}$ & 2.10 & 2.90 & 4.07 & \\
\hline $\begin{array}{c}\text { Predicted } 95 \%- \\
\text { quantile }(\mathrm{kN})\end{array}$ & 1.38 & 2.45 & 3.76 & \\
\hline Accuracy & $62 \%$ & $79 \%$ & $87 \%$ & $76 \%$ \\
\hline
\end{tabular}

the connection, with $I_{P}$ determined using Eq. (1) from Blaß and Görlacher (2002).

$I_{P}=\frac{a b^{3}+a^{3} b}{12}=\frac{b^{4}}{6}$

Joint strength appears to be bounded towards higher moments of inertia of the cross-section. Table 4 lists all mean values, as well as the standard deviation and upper and lower $5 \%$-quantiles. The standard deviation related to the average varied between 26,19 and $28 \%$ for the three edge lengths, with an overall variance of $24 \%$ for the whole series. In addition to the mean, Table 4 also provides the upper and lower $5 \%$-quantiles, the latter commonly used as material strength parameter for structural dimensioning.

The evaluation of the tests on the cylindrical off-axis specimen is shown in Fig. 4. A subsequent statistical analysis showed that the failure interaction of $\sigma_{z}$ and $\tau_{r z}$ at the interface can best be represented by Eq. 2 which represents a strength criterion for orthotropic materials taken from Liu (2001).

$\sigma_{F}=\left(\frac{\sigma_{z}}{\sigma_{z, 0}}\right)^{2}+\left(\frac{\tau_{r z}}{\tau_{r z, 0}}\right)^{2}+\frac{\sigma_{z} \cdot \tau_{r z}}{\sigma_{z, 0} \cdot \tau_{r z, 0}}=1$

Following Eq. 2 failure of the interface is defined by values for $\sigma_{\mathrm{F}}=1$ or higher. The parameters $\sigma_{\mathrm{z}, 0}=0.68 \mathrm{MPa}$ and $\tau_{\mathrm{rz}, 0}=1.37 \mathrm{MPa}$ represent the average values of the experimental strength toward tensile out-of-plane stresses $\sigma_{\mathrm{z}}$ and, respectively, the shear stresses $\tau_{\mathrm{rz}}$, obtained from the results of the offaxis tests (see Fig. 4).

\section{Numerical strength prediction}

\subsection{Numerical model for stress determination}

Stresses at the welded interface were determined using the FEA package ANSYS ${ }^{\circledR}$. In order to reduce the computing time, symmetry was exploited, as shown in Fig. 6. The numerical model is composed of two bonded panels with 

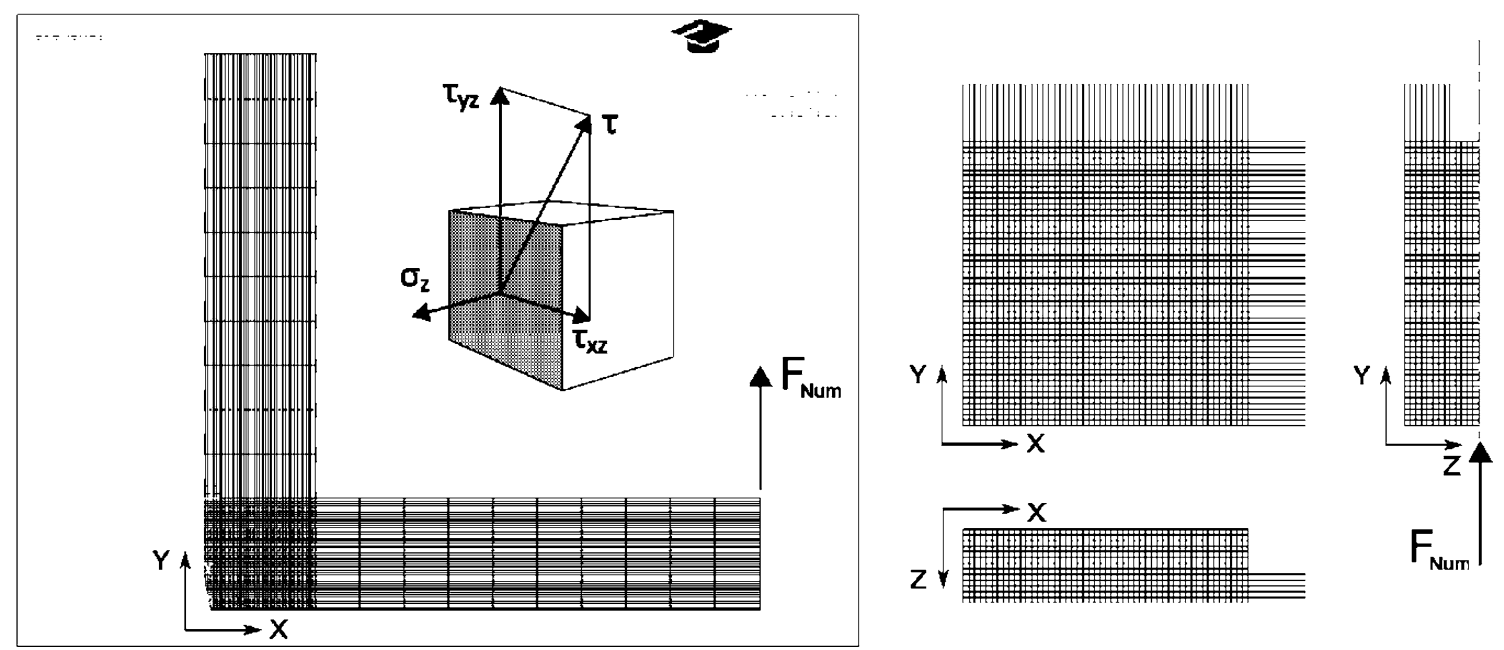

Fig. 6 Numerical model of the experimental setup

Abb. 6 Numerisches Modell des experimentellen Versuchsaufbaus

Sigma-Z [MPa]

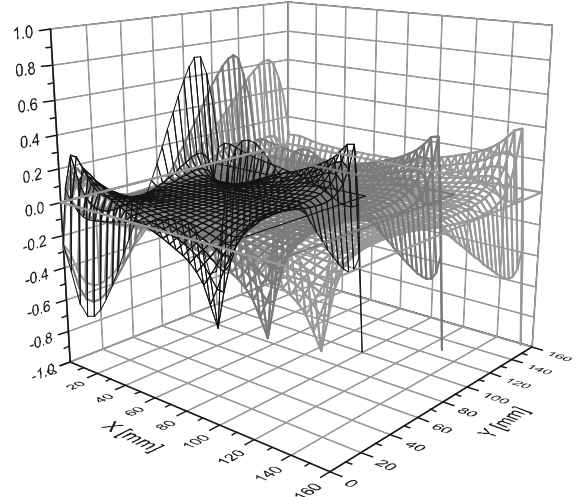

Tau-XZ [MPa]

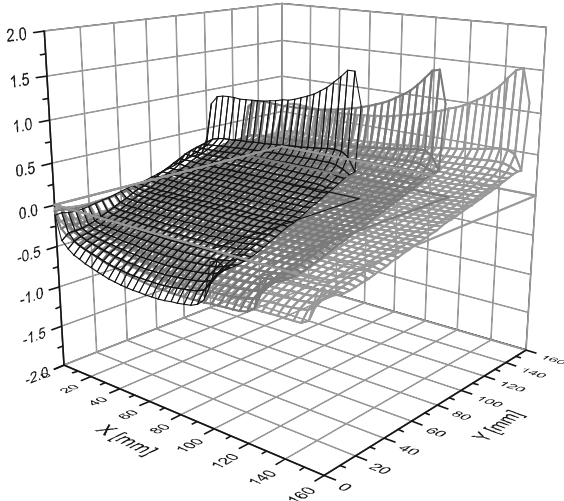

Tau-YZ [MPa]

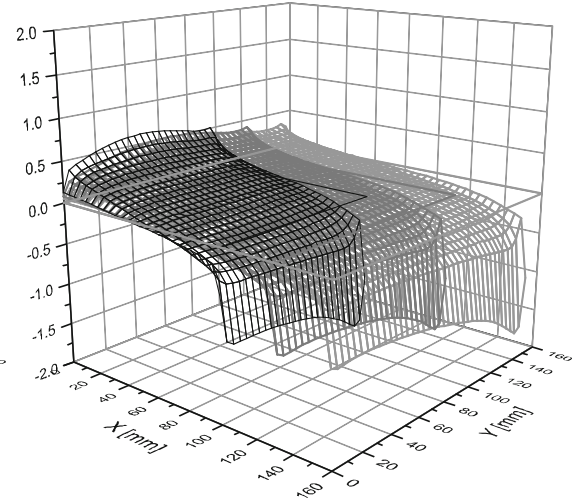

Fig. 7 Distribution of numerically computed stresses $\sigma_{z}, \tau_{X Z}$ and $\tau_{Y Z}$ over the interface for different edge lengths. Each stress state corresponds to the calculated load level resulting in a predicted probability of survival of $50 \%$

Abb. 7 Verteilung der numerisch berechneten Spannungen $\sigma_{z}, \tau_{X Z}$ und $\tau_{Y Z}$ über die Verbindungsfläche für verschiedene Kantenlängen. Jeder Spannungszustand entspricht dem zu einer vorhergesagten Überlebenswahrscheinlichkeit von $50 \%$ berechneten Lastpegels

orthogonal orientations of their respective orthotropic material properties. Local coordination systems, herein indicated by lowercase characters, were defined for each panel, and material properties attributed accordingly, refer to Sect. 2.4. Three-dimensional 8-Node structural solid elements, SOLID185, were used. The area close to the welded bond was modelled with a relatively tight mesh of cubic elements with an edge length of $2 \mathrm{~mm}$. For the rest of the model, longer elements with $20 \mathrm{~mm}$ edge length were used. The welded contact between the two panels was modelled as being completely rigid; thus no specific interface elements were needed.

According to Fig. 6, three different orthogonal stresses, $\sigma_{\mathrm{Z}}, \tau_{\mathrm{XZ}}$ and $\tau_{\mathrm{YZ}}$, in relation to the global coordinates $\mathrm{X}, \mathrm{Y}$ and $\mathrm{Z}$, were considered to describe the stress state at the interface. The computed stresses $\sigma_{Z}, \tau_{X Z}$ and $\tau_{Y Z}$ for specimens with different edge lengths are plotted in Fig. 7.

\subsection{Statistical distribution for probabilistic strength prediction}

Weibull statistics have proven to be an accurate approximation for statistical modelling of brittle failure modes, which was successfully used in previous investigations on welded timber bonds (Vallée et al. 2011; Hahn et al. 2012). The cumulative distribution function for the Weibull probability of survival $P_{s}$ of a structural element can be expressed by Eq. 3 (Bažant et al. 1991): 
$P_{s}=\exp \left[-\frac{V}{V_{r}} \cdot P_{r}(\sigma)\right]$

where $V$ is size of the element, being a length, a surface or a volume, and $V_{r}$ is for the representative measure at which the strength distribution was determined. The statistical distribution $P_{r}$ was proposed by Weibull in form of Eq. 4 (Weibull 1939).

$P_{r}(\sigma)=\left(\frac{\sigma-\sigma_{u}}{\sigma_{0}}\right)^{m}$

where $m$ is the shape parameter and $\sigma_{O}$ is the scale parameter of the Weibull distribution. Low values of $m$ correspond to a high variability of the results while high values indicate a low scattering. For the strength threshold $\sigma_{\mathrm{u}}$ it is convenient to assume that this value is 0 (Bažant et al. 1991). Doing so, Eq. 4 becomes a two parametrical function.

Since the welded interface is not submitted to a single stress, $\sigma$, but to a combination of shear and normal stresses, the formulation of the Weibull probability distribution in Eq. 4 has been extended towards a multi-axial stress state. Although initially developed for isotropic materials failing under uniaxial loads, nothing in the derivations formulated for the Weibull theory limits its extension towards the considered orthotropy and multiaxiality. It has already been extended by Bažant et al. (1991) towards main principal stresses; and subsequently several previous studies, including FRP and timber (Keller and Vallée 2006; Tannert et al. 2012; Vallée et al. 2011; Hahn et al. 2012) did address this issue, and concluded that Weibull theory could be considered. Here, one normal stress vector $\sigma_{\mathrm{z}}$, orthogonal to the surface, is combined with an in-plane shear vector $\tau_{\mathrm{rz}}$. It was decided to use one combined stress measure $\sigma_{\mathrm{F}}$, estimated using Eq. 2, as stress operator in Eq. 4, which is in line with previous investigations mentioned above. Thus, each result of the off-axis tests from Sect. 2.5 can be independently expressed by one parameter from the respective load combination. Since $V$, defined herein as the surface size of the welded bond, is equal to $V_{r}$ for the case of off-axis tests, the probability of survival can be expressed by Eq. 5 .

$P_{s}=\exp \left[-\left(\frac{\sigma_{F, i}}{\sigma_{F, 0}}\right)^{k}\right]$

First $\sigma_{F, i}$ was calculated for each experimental combination of $\sigma_{\mathrm{z}}$ and $\tau_{\mathrm{rz}}$ from the off-axis tests shown in Fig. 4 using Eq. 2. The Weibull parameters $k$ and $\sigma_{F, O}$ are estimated using a linear regression analysis of the statistical distribution of $\sigma_{F, i}$ according to Langlois (1991) and resulted in $k=2.907$ and $\sigma_{\mathrm{F}, 0}=1.145$. The small value of $k$ corresponds to a high variability of the test results, which is characteristic for friction welded timber bonds and as it can be observed by the variation of the experimental results in Fig. 4.

\subsection{Algorithm of probabilistic strength prediction}

The probability of survival $P_{S}$ of the joint is expressed as the simultaneous non-failure of all single constituent finite element $\mathrm{A}_{\mathrm{i}}$, subjected to a combined stress sensor $\sigma_{\mathrm{F}, \mathrm{i}}$. Mathematically $P_{\mathrm{S}}$ can be expressed through Eq. 5 as follows:

$$
\begin{aligned}
P_{S} & =\prod_{i=1}^{n} \exp \left[-\frac{A_{i}}{A_{0}} \cdot\left(\frac{\sigma_{F, i}}{\sigma_{F, 0}}\right)^{k}\right] \\
& =\exp \left[\sum_{i=1}^{n}-\frac{A_{i}}{A_{0}} \cdot\left(\frac{\sigma_{F, i}}{\sigma_{F, 0}}\right)^{k}\right]
\end{aligned}
$$

The representative surface $A_{0}$ is the size of the welded surface from the cylindrical off-axis samples, $k$ and $\sigma_{\mathrm{F}, 0}$ have been estimated previously in Sect. 3.1.

The stresses $\sigma_{\mathrm{Z}}, \tau_{\mathrm{XZ}}$ and $\tau_{\mathrm{YZ}}$, needed for the calculation of $\sigma_{\mathrm{F}, \mathrm{i}}$, are obtained from the FEA. The formulation of $\sigma_{\mathrm{F}, \mathrm{i}}$ in Eq. 2 includes only one shear stress component $\tau_{\mathrm{rz}}$ that is independent from the local orientation of the grains. Therefore, it was decided to use the vectorial sum $\tau_{Z}$ of the two orthogonal shear stress components $\tau_{\mathrm{XZ}}$ and $\tau_{\mathrm{YZ}}$. Doing so, the expression in Eq. 5 can be computed for any given load level $F_{\text {NUM }}$, resulting in a corresponding probability of survival of the given geometry. A global probability of survival of $50 \%$ represents the experimental mean of the test results; hence, the lower $5 \%$-quantile corresponds to a probability of survival of $95 \%$.

\subsection{Analytical linear elastic stress approach}

The probabilistic strength prediction method will be compared to the results of a simplified linear elastic stress analysis approach in order to evaluate its suitability for consideration of strong size effects. The linear elastic approach is based on the method for the design of horizontally loaded wall elements made of CLT panels developed by Blaß and Görlacher (2002). According to that, the shear stresses $\tau_{\max }$ due to torsion from Eq. 7 are compared to a threshold value, herein labelled $\tau_{\text {lim }}$. For this approach the threshold value for shear is taken as $\tau_{\mathrm{rz}, 0}$ from the results of the off-axis tests. Substituting $\tau_{\lim }$ for $\tau_{\max }$ in Eq. 7 the maximum force $F_{\max }$ can easily be determined.

$\tau_{\max }=\tau_{\lim }=\frac{M_{T}}{I_{P}} \cdot \frac{b}{2}=\frac{F \cdot e}{I_{P}} \cdot \frac{b}{2}=\tau_{r z, 0}$ 


\subsection{Results of strength prediction}

The numerical joint strength has been computationally predicted for the three different geometrical configurations experimentally investigated. In addition to the statistical mean, the upper and the lower $5 \%$-quantile of each series has been predicted in order to model the inherent scattering of the results. All data is listed in Table 4.

Similar to the experimental results, the numerically predicted mean of the joint strength in Fig. 8 is positively correlated to the polar moment of inertia, but converges strongly with increasing surface size. The curve for the predicted mean shows good agreement with the curve fitting of the experimental means of around $80 \%$.

Joint strengths obtained using the analytical approach, displayed in Fig. 8, increase much more when joint size is increased. For samples with the longest edge length of $160 \mathrm{~mm}$, the analytical joint strength corresponds to $270 \%$ of the experimental value and $300 \%$ of the probabilistic predicted mean. Compared to this approach, the probabilistic method very accurately considers size effects for strength prediction.

Furthermore the comparison between the experimental results and the predicted values in Table 4 and Fig. 8 shows good agreement. The accuracy in predictions increases with increasing edge length. The experimental mean from all series could be predicted with an overall accuracy of $78 \%$, varying between $61 \%$ for $100 \mathrm{~mm}$ edge length and $91 \%$ for $160 \mathrm{~mm}$ edge length. Good agreement is also obtained for the lower $5 \%$-quantiles of all series. From a $100 \mathrm{~mm}$ edge length towards $160 \mathrm{~mm}$ the numerical prediction varies between 60 and $98 \%$ of the experimental data. Good accordance occurs as well for the prediction of the $95 \%$-quantile, where the numerical values differ between 62 and $87 \%$ of the experimental results.

\section{Discussion}

\subsection{Experimental results}

Figure 5 shows the experimental data for the tested L-specimens plotted against the joint edge length. A direct relationship between the surface size and the interface resistance can be observed. The fitting curve rises almost linearly from $1.67 \mathrm{kN}$ for the specimens with an edge length of $100 \mathrm{~mm}$ up to $3.24 \mathrm{kN}$ for specimens with $160 \mathrm{~mm}$ edge length. For some specimens failure did not occur simultaneously in both welded interfaces between the two vertical elements and the horizontal board. These specimens still showed reduced load bearing capacity after fracture of one welded side. The displacement could furthermore be increased and $F$ rises again until total failure. The load level of the first crack was considered as the representative value of the sample.

The results from the off-axis tests allowed quantifying a stress-based failure criterion of the welded interface that takes into account the interaction between normal stresses $\sigma_{\mathrm{z}}$ and shear stresses $\tau_{\mathrm{rz}}$. The scattering of the results, is significant. The same can be concluded regarding the shape parameter $k=2.907$ from the Weibull distribution of the stress operator $\sigma_{\mathrm{F}, \mathrm{i}}$, since low values of $k$ indicate large scattering.
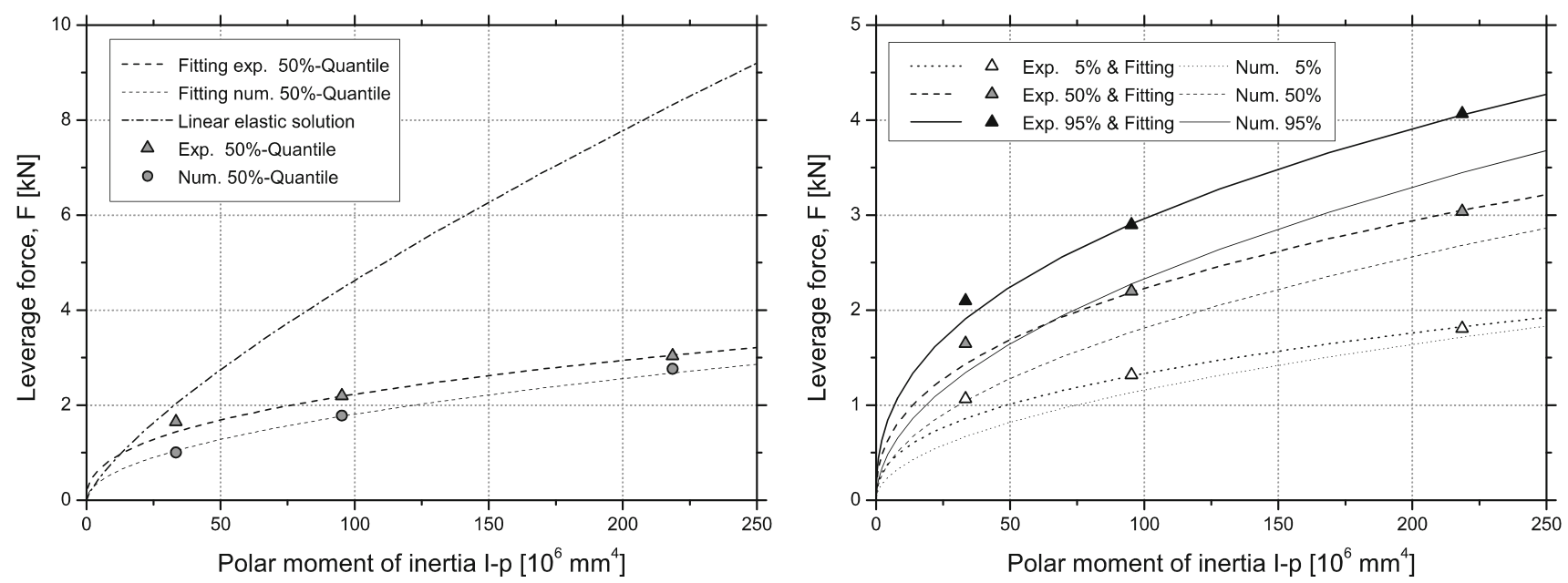

Fig. 8 Comparison between experimental, numerical and analytical average joint strength (left) and experimental and predicted joint capacities represented by 5, 50 and $95 \%$ quantile values (right)

Abb. 8 Vergleich zwischen experimentell, numerisch und analytisch ermittelter durchschnittlicher Festigkeit (links) und experimentelle sowie numerische Verbindungskapazitäten, dargestellt durch die 5, 50 und $95 \%$-Quantil-Werte der Verteilung (rechts) 


\subsection{Numerical calculation}

Computed graphs for the stress components $\sigma_{z}, \tau_{x z}$ and $\tau_{y z}$, corresponding to a load level where a probability of survival of $50 \%$ was calculated, are shown in Fig. 7. In addition to the tensile stresses normal to the interface, Fig. 7 also shows important amounts of compressive stresses, represented by negative values of $\sigma_{z}$. The experimentally validated failure criterion from Sect. 2.4 is defined only for tensile stresses above zero, although compressive stresses are thought to act positively in the sense that shear strength increases. The determination of the global probability of survival, which is by essence given by the product of the individual probabilities of survival of each single element, is still largely dominated by the most stressed elements in the zones of tensile stresses. This makes the contribution of "lessstressed" elements almost negligible. As a result, suppressing the positive influence of compressive stresses is unlikely to flaw the overall result significantly, which has been proven in previous studies (Keller and Vallée 2006; Tannert et al. 2012; Vallée et al. 2011; Hahn et al. 2012). As shown in the figures, stresses concentrate towards the edges, indicating that load transfer mainly takes place in the peripheral zone, while the inner stresses remain negligible. Furthermore, it is significant that the shear stresses are concentrated at the edges that are orientated in the direction of the introduced load respectively the clamp of the specimen. This is different to intersections within CLT panels, where shear stresses are distributed more homogeneously over the surface. For the validation of the strength prediction method, however, this stress distribution can be assumed as a good representation of the actual experimental situation, while for CLT panels another stress distribution has to be considered.

For better illustration the significantly concentrated stresses have been plotted separately in Fig. 9, namely, at the vertical edges, the stresses normal to the interface and the shear stresses in the YZ-plane and, along the horizontal edges of the cross-section, the shear stresses in the
XZ-plane. For the same probability of survival the maximum values of stresses decrease with increasing edge length. For example, for the biggest specimens with an edge length of $160 \mathrm{~mm}$, the critical normal stresses around position $(0 ; 140)$ in Fig. 7 respectively 9 are lower with around $0.6 \mathrm{MPa}$ than for specimens with the shortest edge length of $100 \mathrm{~mm}$, where around $0.7 \mathrm{MPa}$ are calculated at the equivalent position $(0 ; 90)$. For the shear stresses $\tau_{\mathrm{YZ}}$ and $\tau_{\mathrm{XZ}}$ in Figs. 7 and 9 the same effect can be observed. In general, with increasing size, the highest, most critical values at the edges decrease. Only at the corner near to position (e;e) the level of the shear stresses remains equal respectively increases slightly towards longer edge lengths e. As a consequence the stress operator $\sigma_{\mathrm{Fi}}$ increases at that position with increasing edge length, while $\sigma_{\mathrm{Fi}}$ at the position of the two remaining critical stress concentrations decreases. It can be concluded that with increasing edge length the stresses at the critical position (e;e) become more important within the strength prediction algorithm. Thus, for bigger samples the same value of failure probability is obtained before equal stress levels are achieved in bigger parts of the interface. The latter finding clearly describes the influence of surface size on the joint strength.

\subsection{Capacity prediction}

There is good agreement between the numerically predicted values and the experimental results: for the samples with an edge length of 130 and $160 \mathrm{~mm}$ the $5 \%$-quantiles were predicted with an accuracy of $80 \%$ or higher. The results for an edge length of $100 \mathrm{~mm}$ are significantly underestimated. It can be stated that the accuracy increased with increasing edge length. One possibility is that the aforementioned disregard of advantageous compressional stresses (see Sect. 4.2) in the calculation of $\sigma_{F, i}$ has an important influence on the predicted results for shorter edge lengths.

The strength prediction algorithm strongly depends on the defined failure criterion from Sect. 2.4, thus on the results of the off-axis tests from which they were drawn. As
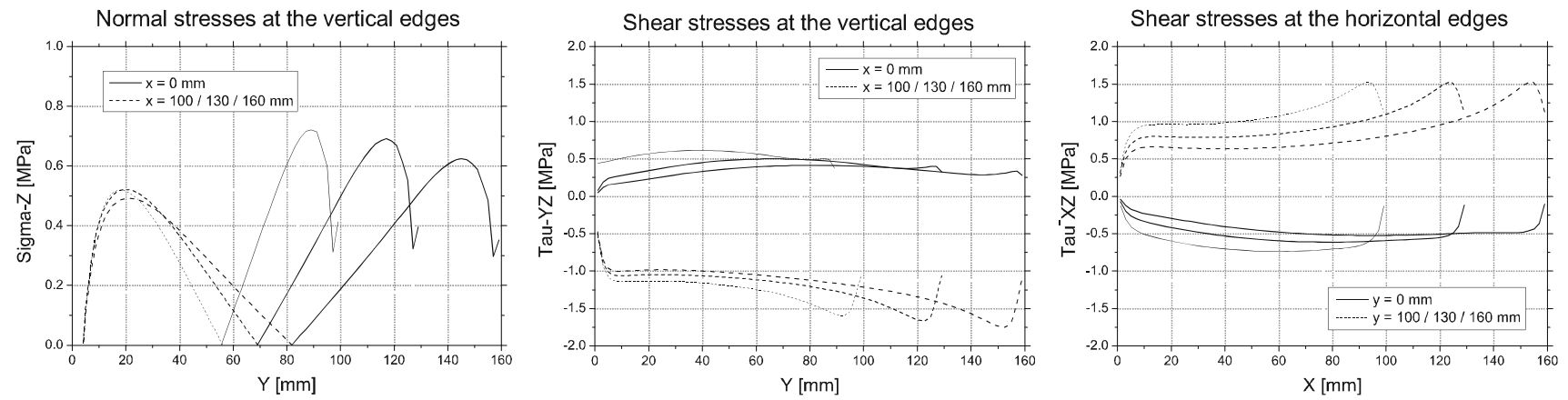

Fig. 9 Numerically computed stress states at the position of the most critical stress concentrations from Fig. 7 Abb. 9 Numerisch berechnete Spannungszustände an der Position der kritischen Spannungsspitzen aus Abb. 7 
it was stated in Sect. 4.1, the statistical variance of these tests, expressed by a low shape parameter $k$, is relatively high. It cannot be excluded that the chosen cutting process for the fabrication of the cylinders had an important influence on the scattering of the results. Micro-cracks may occur for example due to vibrations during the milling process, which can reduce the resulting strength of the interface. No matter how carefully the manufacturing is carried out, these vibrations couldn't be avoided completely during the cutting process.

\section{Conclusion}

Cross-wise welded timber joints were produced and tested under torsion in order to shed light on the structural behaviour of such joints in potential bracing cross-laminated timber (CLT) panels.

First, two different welding technologies were tested and their corresponding load bearing capacity was compared. It was found that a circular vibrational movement during welding is more advantageous over linear vibration welding. The results were also compared to glued connections achieved by means of a commonly used adhesive based on polyurethane. The strength of welded specimens represents $40 \%$ of corresponding glued connections.

Second, the surface size of the welded interface was increased in two steps in order to investigate the influence of size on resulting joint strength. Within the investigated geometrical range, bearing capacity of the specimens is linearly correlated to the surface size.

Furthermore the mechanical resistance of the welded interface was experimentally characterised. An adapted test-setup was developed in order to simulate the combination of stresses occurring at the interface zone of the L-shaped specimens tested in bending. The test results were used to define a failure criterion for further application in a numerical strength prediction algorithm.

The probabilistic strength prediction method allowed the prediction of the experimental mean values with an overall accuracy of $80 \%$. In addition, the inherent variability of the results could be predicted by calculating the numerical upper and lower $5 \%$-quantiles which showed a very good agreement with the experimental values. The comparison between experimental and numerical results objectively validated the applied proceeding of strength prediction.

If projected at the level of welded CLT panels, estimations of simple case studies on horizontally loaded bracing walls showed that shear stresses expected in those elements can be transferred by friction-welded joints. According to the results of the off-axis tests under pure shear, bonds achieved by this technology can have a minimum shear resistance of $0.97 \mathrm{MPa}$.
Further research has to extend the investigations on more complex systems composed of more than one intersection point, in order to understand the simultaneous interaction of friction welded bonds within CLT panels.

Acknowledgments The present research work is funded by the Swiss National Foundation and is part of the project "SNF-Synergia Project no. CRSI22_127467/1".

\section{References}

Balzani C, Wagner W, Wilckens D, Degenhardt R, Büsing S, Reimerdes HG (2012) Adhesive joints in composite laminates: a combined numerical/experimental estimate of critical energy release rates. Int J Adhes Adhes 32:23-38

Bazant ZP (2005) Scaling of structual strength, 2nd edn. Elsevier, Oxford

Bažant ZP, Fellow ASCE, Xi Y, Reid SG (1991) Statistical size effect in quasi-brittle structures: I. Is Weibull theory applicable? J Eng Mech 117:2609-2622

Bažant ZP, Fellow ASCE, Novák D (2000a) Probabilistic nonlocal theory for quasi-brittle fracture initiation and size effect. II Application. J Eng Mech 126(2):166-174

Bažant ZP, Fellow ASCE, Novák D (2000b) Probabilistic Nonlocal Theory for quasi-brittle Fracture Initiation and Size Effect. I Theory. J Eng Mech 126(2):166-174

Blaß HJ, Görlacher R (2002) Zum Trag- und Verformungsverhalten von Brettsperrholz-Elementen bei Beanspruchung in Plattenebene. Bauen mit Holz 11:34-40

Da Silva LFM, Das Neves PJC, Adams RD, Spelt JK (2009a) Analytical models of adhesively bonded joints part I: literature survey. Int J Adhes Adhes 29(3):319-330

Da Silva LFM, Das Neves PJC, Adams RD, Wang A, Spelt JK (2009b) Analytical models of adhesively bonded joints part II: comparative study. Int J Adhes Adhes 29(3):331-341

Delmotte L, Mansouri HR, Omrani P, Pizzi A (2009) Influence of wood welding frequency on wood constituents chemical modifications. J Adhesion Sci Technol 23:1271-1279

Freudenthal AM (1968) Statistical approach to brittle fracture (chapter 6). In: Liebowitz H (ed) Fracture - an advanced treatise, vol 2. Academic Press, New York, pp 591-619

Gfeller B, Pizzi A, Zanetti M, Properzi M, Pichelin F, Lehmann M, Delmotte L (2003) Wood bonding by vibrational welding. J Adhesion Sci Technol 17:1573-1589

Gliniorz KU, Natterer J (2000) Holzschweißen: Innovative Verbindungstechnologien im Holzbau. Tagungsunterlagen, Symposium der Lignaplus/Weltmesse für die Forst- und Holzwirtschaft. Hannover/D.:79-83

Hahn B, Vallée T, Stamm B, Weinand Y (2012) Experimental investigations and probabilistic strength prediction of linear welded double lap joints composed of timber. Int J Adhes Adhes 39:42-48

Hermann LR (1965) Elastic torsional analysis of irregular shapes. J Eng Mech Div ASCE 91:11-19

Illing S (2002) Untersuchung des Verfahrens und der Produkteigenschaften beim Pyrolyse-Schweißen von Holz durch Reibschweißen. Diploma Thesis. Ecole Polytechnique Fédérale de Lausanne EPFL

Keller T, Vallée T (2006) Adhesively bonded lap joints from pultruded GFRP profiles part II: joint strength prediction. Compos B Eng 36:341-350

Langlois R (1991) Estimation of Weibull parameters. J Mater Sci Lett 10:1049-1051 
Liu JY (2001) Strength criteria for orthotropic materials. Eighth annual international conference on composite engineering ICCE, Tenerife (E)

Pan B, Qian K, Xie H, Asundi A (2009) Two-dimensional digital image correlation for in-plane displacement and strain measurement: a review. Meas Sci, Technol 20

Pizzi A, Mansouri HR, Leban JM, Delmotte L, Pichelin F (2011) Enhancing the exterior performance of wood joined by linear and rotational welding. J Adhes Sci Technol 25:2717-2730

Properzi M, Leban JM, Pizzi A, Weiland S, Pichelin F, Lehmann M (2005) Influence of grain direction in vibrational wood welding. Holzforschung 59:23-27

Pupurs A, Krasnikovs A, Varna J (2013) Energy release rate based fiber/matrix debond growth in fatigue part II: debond growth analysis using paris law. Mech Adv Mater Struct 20(4):288296

Serrano E (2004) A numerical study of the shear-strength predicting capabilities of test specimens for wood-adhesive bonds. Int $\mathbf{J}$ Adhes Adhes 24:23-35

Stamm B, Weinand Y (2006) Joining wood by friction welding: fabrication of multi-layered compenents. world conference in timber engineering WCTE. Portland (USA)
Stamm B, Natterer J, Navi P (2005a) Joining wood by friction welding. Holz Roh- Werkst 63:313-320

Stamm B, Natterer J, Navi P (2005b) Joining of wood layers by friction welding. J Adhes Sci Technol 19:1129-1139

Stamm B, Windeisen E, Natterer J, Wegener G (2005c) Thermal behaviour of polysaccharides in wood during friction welding. Holz Roh- Werkst 63:388-389

Stamm B, Weinand Y, Hahn B, Rossmair G (2011) Influence of the moisture content on the shear strength of welded wood-to-wood connections. COST Action FP0904 Biel $(\mathrm{CH})$

Suzuki S (1987) Stress analysis of cemented lap joints. IngenieurArchiv 57:307-314

Tannert T, Vallée T, Hehl S (2012) Experimental and numerical investigations on adhesively bonded timber joints. Wood Sci Technol 46(1):579-590

Vallée T, Tannert T, Ganne-Chédeville (2011) Capacity Prediction of Welded Timber Joints. Wood Sci Technol 46:333-347

Weibull W (1939) A statistical theory of strength of materials. In: Proceedings of the Royal Swedish Institute, Research No.151, Stockholm, Sweden

Weinand Y (2009) Innovative timber constructions. J Int Assoc Shell Sp Struct 50:111-120 